\title{
DASEIN E MUNDO: UMA CRÍTICA AO CONHECIMENTO COMO
}

ATIVIDADE TEORÉTICA.

\author{
$\underline{\text { Natan Luiz Neri de Sousa }}{ }^{1}{ }^{2}$; Tatiane Pereira Boechat \\ 1. Bolsista PIBIC/FAPESB, Graduando em Filosofia, Universidade Estadual de Feira de Santana, e-mail: \\ natanluizneri@gmail.com
}

2. Orientador, Departamento de Ciências Humanas e Filosofia, Universidade Estadual de Feira de Santana, e-mail: tatiboechat@uefs.br

PALAVRAS-CHAVE: Dasein; Mundo; Conhecimento.

\section{INTRODUÇÃO}

Heidegger em Ser e Tempo assume a tarefa de colocar a questão do sentido do ser. Essa tarefa consiste em um estudo do comportamento existencial do homem (Dasein), isto é, do homem enquanto abertura e não como uma substância pensante, ou um animal racional, mas como o lugar onde se manifesta a diferença ontológica. $\mathrm{O}$ intuito do filósofo com uma analítica existencial não é uma análise do ente homem, mas sim do domínio da abertura no qual é possível aceder ao sentido do ser e sua verdade. Portanto, é entendido que o perguntar é algo próprio do homem, entretanto, ao se fazer a pergunta pelo sentido do ser, de certa maneira, é necessário que seu sentido já esteja disposto, ou seja, já lidamos previamente com o sentido daquilo que (é), e isso aponta que o Dasein se move numa pré-compreensão do ser. Dito isto, a proposta do projeto é investigar como se configura à crítica ao conhecimento como atividade teorética, presente na obra Ser e Tempo, ou seja, a crítica ao homem entendido como sujeito do conhecimento que se reporta de forma objetiva ao ente intramundano, como pensou a modernidade. A representação pensante é a forma como a modernidade aborda a realidade das coisas, desse modo, a relação sujeito-objeto se constituiu como a forma hegemônica de acesso do homem com as coisas. Portanto, procuramos investigar quais as consequências do projeto heideggeriano presente em Ser e Tempo no que concerne a esse modelo moderno vigente. Este projeto justifica-se na medida em que a investigação nos coloca no cerne de uma crítica que mobiliza a forma como a filosofia pensou o homem ao longo da história e da maneira deste modo de lidar com os entes. Posto que, Heidegger procura apresentar uma "ontologia fundamental" que se funda na analítica existencial, ou seja, no Dasein enquanto existência, no qual é a base da compreensão não temática do ente que lhe é acessível.

\section{MATERIAL E MÉTODOS OU METODOLOGIA (ou equivalente)}

A metodologia adotada é a da pesquisa bibliográfica, cujo objetivo central se constitui numa consulta sistemática e cuidadosa às fontes escritas de filósofos e comentadores relacionados ao tema e ao objetivo do projeto. O desenvolvimento da pesquisa tem como passo investigativo fundamental a leitura e análise de textos e conferências publicadas de Heidegger que estão relacionadas à questão proposta, bem como, outros meios impressos e digitais da literatura comentada. 
A filosofia moderna no que concerne a orientação ontológica básica interpreta 0 homem ao modelo das coisas, ou seja, como res. Em um primeiro momento pode-se identificar através de Descartes a polarização entre o sujeito ( res cogitans) e as coisas (res extensa), o primeiro interpretado como uma coisa pensante, determinando assim a distinção sujeito-objeto que vingou durante todo período moderno. Para Heidegger todo esse contexto apresentado na modernidade é viabilizado por uma interpretação do ser como essência, no qual o ser é confundido com o que há de mais entificador no ente, ou seja, a sua quididade. Desse modo, no ideal moderno a relação sujeito-objeto pressupõe a separação desses dois elementos: sujeito cognoscente - objeto conhecido, efetivando o conhecimento como uma atividade teórica que, fundamentada numa ousiologia do ser, legitima a separação consciência - mundo, recolocando o sujeito (o $\mathrm{Eu}$ ) como fundamento do conhecimento, pois ele é o limite e a condição para que algo seja conhecido. No entanto, o conhecimento científico, este que se sustenta em todo este escopo moderno, geralmente é restringido à sensibilidade. Como afirma Stein (2006): "Esse tipo de conhecimento poderia, então, ser considerado um saber que se reduz ao mundo natural. É corrente entre nós, a expressão ele é um naturalista". Nesse sentido, Heidegger já no parágrafo $\$ 11$ de Ser e Tempo aborda a dificuldade que essa exigência naturalista impõe à filosofia, a saber, elaborar a ideia de "mundo natural". O filósofo procura nesse parágrafo explicitar uma delimitação mais radical da problemática ontológica face às pesquisas ônticas, a qual requer afastar-se da ambiguidade do termo "mundo" recorrendo à questão que a problemática ontológica impõe: "uma ideia explícita de mundo em geral". Esta ideia de mundo não se encontra nos elementos naturais, pois, mundo, para Heidegger, já é em si mesmo um existencial constitutivo do Dasein.

Contudo, a analítica existencial nos revela que o modo de ser do Dasein na sua cotidianidade é o da ocupação e que é nela que se realiza a mundanidade do mundo. Em Ser e Tempo "mundo" não é um ente entre outros entes, mas o horizonte de sentido do Dasein, que constitui a rede de remissões de um instrumento para com o outro. Como no exemplo de um giz que remete ao quadro, por conseguinte à cadeira, por conseguinte refere-se aos alunos, que se refere à escola e que de forma indefinida ( mundo dentro de mundo) formam círculos de familiaridade cada vez mais complexos, que efetuam a "mundanidade" do mundo. É a partir do mundo circundante, isto é, do mundo próximo cotidiano que parte Heidegger, procura ele explicitar que a forma imediata do Dasein lidar com os entes intramundanos não ocorre através de um conhecimento puramente mental e "perceptivo", mas que, ao se ocupar, no uso, é que o ente se torna primeiramente acessível.

Heidegger designa esses entes que vêm ao encontro do Dasein no mundo circundante de instrumentos - é necessário abandonar as concepções modernas discutidas acima- Pois, instrumento não deve ser entendido como uma coisa (res). Instrumento é aquilo com que se lida na ocupação, desse modo nunca é isolado, ele é em sua essência uma referência conjuntural, ou seja, está sempre subordinado a uma multiplicidade de referências. o instrumento é sempre " algo para" ( $U m-z u)$, ou seja, sempre remete a uma funcionalidade. No entanto, nos deparamos com a experiência da ruptura, que para além de nos revelar uma rede tácita de relação entre os instrumentos nos revela também a possibilidade do ente não estar a mão. Portanto, o instrumento 
enquanto zuhandenheit é o modo originário que o ente vem ao encontro do Dasein no mundo. Entretanto, ele não se apresenta apenas ao modo da zuhandenheit, mas também como vorhandenheit (que não está a mão). Contudo, Albuquerque (2015) nos alerta que essa oposição entre os dois modos de ser do ente não é determinada pelo Dasein. A característica principal do vorhandenheit é que ele já não é mais parte da totalidade conjuntural, no entanto, ele vêm ao nosso encontro, assim tal como ele é. Desse modo, os dois modos-de-ser do ente são também modos de acesso ao fenômeno, um de forma implícita, no qual o Dasein já é/estar no mundo e outro que expõe esse mundo no qual o Dasein desde sempre em sua cotidianidade está imerso.

\section{CONSIDERAÇÕES FINAIS (ou Conclusão)}

As investigações logradas nesta pesquisa nos colocam no cerne da crítica do conhecimento como atividade teorética, no qual o problema do ser é anterior a qualquer problema epistemológico. Perseguindo o caminho fenomenológico percorrido por Heidegger, nos deparamos com a analítica existencial como via de acesso para a questão mais fundamental e, a partir dessa analítica do ente humano no seu ser, pode-se identificar a posição heideggeriana no que diz respeito ao conhecimento. Portanto, para Heidegger, o problema elementar no que concerne ao conhecimento é que as filosofias assentadas numa ousiologia, tem como pressuposto investigativo o conhecimento teorético, no qual se estabelece a relação sujeito-objeto, desse modo se mostram ineficientes para pensar o caráter transcendental dessa relação..

Portanto, a crítica ao conhecimento apresentada em Ser e Tempo não deixa de se configurar como um ponto de partida para se estabelecer as justificativas ontológicas no qual procura explicitar a relação originária entre Dasein e os entes, pois, como podemos constatar durante o desenvolvimento da pesquisa, os entes nos vêm ao encontro no mundo de forma relacional, de forma que o modo originário de estar-junto aos entes é de caráter não reflexivo, apresentam-se ao modo do "zuhandenheit". Dessa forma, a apreensão do ente como objeto (vorhandenheit) a partir de um sujeito "desprovido" de mundo, não considera a rede de significações. Antes mesmo de o ente se apresentar como objeto, ele vem ao encontro no seu caráter relacional, pois o objeto (vohandenheit) se apresenta como derivado do instrumento (zuhandenheit), sendo assim, podemos asserir que a possibilidade de se chegar a um conhecimento teorético se perfaz na familiaridade do Dasein junto ao mundo.

\section{REFERÊNCIAS}

HEIDEGGER, M. Ser e Tempo - parte I. Trad. Marcia de Sá Cavalcante. RJ: Vozes, 1998.

Ser e Tempo. Trad. Fausto Castilho. RJ: Vozes, 2012.

. Introdução à Filosofia. São Paulo: Martins Fontes, 2009. 
ALBUQUERQUE, J.F.S. A ciência moderna no primeiro Heidegger: a interpretação heideggeriana ao comportamento científico. Vitória da Conquista: edições UESB, 2015

BLANC, M. F. O fundamento em Heidegger. Lisboa: Piaget, 1984.

.Exisência,, ipsiedade e ser em "Ser e Tempo" de Martin Heidegger. Revista filosófica de Coimbra - n49, 2016, p. 111 - 144.

O programa filosófico de Heidegger. Phainomenon revista de fenomenologia. $\mathrm{N}^{\circ} 24,2012$. P. $125-166$.

CASANOVA, M.A. Compreender Heidegger. Rio de Janeiro: Vozes, 2011.

COLOMER, Eusebi, El pensamento alemán de Kant a Heidegger. Barcelona: Editorial Herder, 1990.

DUBOIS, Christian. Heidegger : introdução a uma leitura. Trad. Bernardo Barros, Rio de Janeiro, Jorge Zahar, 2004.

STEIN, Ernildo. Pensar é pensar a diferença: filosofia e conhecimento empírico. 2 ed, Ijuí, Ed Unijuí, 2006.

STEIN, Ernildo. Mundo vivido: das vicissitudes e dos usos de um conceito da fenomenologia. Porto Alegre, EDIPUCRS, 2004

STEIN, E. Seis estudos sobre Ser e Tempo. Petrópolis: Vozes, 1988.

STEIN, E. Compreensão e Finitude: estrutura e movimento da interrogação heideggeriana. Ijuí: Ed. Unijuí, 2001.

ZARADER, M. Heidegger e as palavras da origem. Lisboa: Piaget, 1990. PASQUA, Hervé, Introdução à leitura de Ser e Tempo de Martin Heidegger. Lisboa, Instituto Piaget, 1993. 